\title{
De guineus, lleons, llops i pastors: domini i govern en el pensament polític de Llull
}

\author{
Josep Maria Ruiz Simon \\ Universitat de Girona \\ josepm.ruiz@udg.edu
}

\section{Resum}

La força i el frau són, segons una vella doctrina ciceroniana, els elements que configuren la part animal de la política. Dante, a la Commedia, va identificar aquests conceptes amb les dues causes de la injustícia que el cel castiga i va usar la seva distinció en el principal criteri de demarcació entre els territoris infernals. Aquest article parteix del relat que Dante fa del que va sentir al cercle de l'Infern on es troba Guido da Montefeltro condemnat per haver aconsellat a Bonifaci VIII el recurs al frau per tractar la quiestió del consell i de la relació entre el saber i el poder. I proposa la lectura del Llibre de les bèsties de Ramon Llull com un mirall en què l'autor, d'acord amb aquella doctrina i amb la tradició literària de les faules animalístiques, recorre a les feres per instruir el príncep sobre els secrets del domini, amb unes lliçons que parlen del poder de la força i del poder de l'engany i que deixen al marge el discurs sobre la justícia que defineix el bon govern.

Paraules clau: Ramon Llull; Dante; miralls de príncep; faules animalístiques; astúcia; poder.

\begin{abstract}
According to an old Ciceronian doctrine, force and fraud are the elements configuring the animal part in politics. In the Commedia, Dante identified these concepts with the two causes of injustice punished by the heavens and used his distinction in the main criterion to mark off the infernal territories. This article comes from the story told by Dante of what he felt in the Inferno circle where he met Guido da Montefeltro, who had been condemned for having advised Boniface VIII to use fraud, to deal with the council and about the relationship between knowledge and power. He makes a suggestion to read Ramon Llull's The Book of the Beasts as a mirror where the author, following that doctrine and the literary tradition of animalistic fables, uses beasts to instruct the prince in the secrets of domination, with lessons on the power of force and the power of deceit, leaving aside the discourse on justice that defines good governance.
\end{abstract}

Keywords: Ramon Llull; Dante; prince mirrors; animalistic fables; cunning; power. 


\section{El saber, el poder i la qüestió del mal consell}

La qüestió que vull tractar s'amaga sota la closca de l'història que Dante conta sobre el que va veure i va sentir a la vuitena fossa del cercle vuitè de l'Infern. És allà on ell i Virgili, després d'haver escoltat el relat d'Ulisses, es troben Guido da Montefeltro. Guido, a qui Villani descriu com l'home més sagaç i més subtil que corria per la Itàlia de la seva època, ${ }^{1}$ és un dels grans personatges històrics de la Commedia. La seva biografia està marcada, com la de Llull i la de molts altres com el mateix Dante, per una conversió. ${ }^{2}$ Si fa o no fa al bell mig del camí de la seva vida, Ramon es va convertir, com molts laics del seu temps, a la penitència. Poc abans d'arribar a la fi de la seva amb 73 anys, Guido, un condottiero gibel-lí reconciliat a les seves velleses amb el papat, va deixar la cavalleria per entrar en l'ordre dels franciscans. El fet que aquest decisió no impedís, ans el contrari, que Dante i Virgili el trobessin al reialme de Satanàs pot fer somriure els coneixedors de la Vita Coetanea lul.liana, on s'explica el somni que Llull hauria tingut durant la seva famosa crisi de Gènova. ${ }^{3}$

El significat profund d'aquest somni lul.lià fa literàriament inversemblant que Ramon, un cop difunt, acabés conversant també amb hàbit franciscà a l'infern amb el condottiero convertit en frare menor. ${ }^{4}$ Però això no impedeix que la vuitena fossa del cercle infernal vuitè sigui una immillorable porta d'accés a la realitat política que Llull i Dante van compartir; una realitat que el mateix Guido descriu amb molta precisió, en relació a un dels seus moments, quan, tot evocant el pecat que l'ha portat allà on és, recorda que el papa, Bonifaci VIII, el «príncep de tots els fariseus», estava en guerra, prop del Laterà, no amb els infidels que havien conquerit recentment Acre, sinó amb altres

1. «I Ghibellini di Romagna colli usciti di Bologna feciono loro capitano di guerra Guido conte di Montefeltro, savio e sottile d'ingegno di guerra più che niuno che fosse al suo tempo" (Giovanni Villani, Nuova cronica, edizione critica a cura di Giovanni PorTa, Fondazione Pietro Bembo, Parma: Ugo Guanda Editore, 1990-1991, t. I, l. VIII, c. 44, edició electrònica www.liberliber.it, p. 173).

2. Utilitzo la paraula "conversió" en el sentit que tendia a tenir a l'Edat Mitjana, quan solia fer referencia no a l'adopció d'una fe o una llei religioses, sinó a un canvi radical de vida definit per la voluntat de viure d'una manera més pietosa.

3. Aquest somni s'hauria esdevingut tres anys abans de la conversió de Guido, mentre el cavaller italià, aleshores excomunicat, feia de capità dels gibel.lins de Pisa i proposava aliances al rei d'Aragó. El relat presenta a Ramon, febrós, davant la terrible alternativa de prendre l'hàbit de sant Domènec i salvar així la seva ànima o de prendre l'hàbit de sant Francesc i salvar la seva Art. Llull, convençut que l'Art havia de permetre la salvació de molts altres, elegeix la seva pròpia damnació i demanà l'hàbit dels menors al guardià del convent en què està allotjat, que li promet que l'hi donarà quan sigui més a prop de la mort. Cfr. Ramon Llull, Vita coetanea, IV, 20-24 (ROL VIII, 1980, p. 284-288). És obvi que, d'acord amb els plantejaments lul.lians, si sant Francesc i un querubí negre i diabòlic s'haguessin disputat l'ànima de Ramon arran d'aquest somni, el resultat hagués estat el contrari del de la disputa que, segons Dante, hauria portat Guido a l'infern. Cfr. DANTE, Inferno, XXVII 112-120.

4. Cfr. De fine, pròleg, ROL IX, 1981, p. 250-251. 
cristians. ${ }^{5}$ Més endavant, quan Dante arribi a l'esfera de Venus, sentirà una descripció semblant en boca d'una altre convers il.lustre, Folquet de Marsella, el trobador que va deixar la literatura i la vida mundanes per prendre els hàbits cistercencs i que, un cop nomenat bisbe de Tolosa, es va aliar amb Simó de Montfort i el papat en la croada contra els albigesos, que va fer cremar a milers. Tot $\mathrm{i}$ aquest aspecte més aviat fosc del seu currículum, Folquet es lamentarà per dos cops del poc que el papa, assedegat com està de Florència, té en la memòria Terra Santa. I caracteritzarà Bonifaci VIII, com un pastor convertit en llop. ${ }^{6}$ Aquesta mateixa imatge del pastor convertit en llop es troba repetidament en el Liber de praedicatione, una obra que Llull va compondre el desembre de 1304, quan la seu romana era vacant arran de la mort sobtada de Benet XI; el mateix any, per tant, en què, segons alguns erudits, Dante va començar a escriure la Commedia. ${ }^{7}$

La descripció de la realitat contemporània que es troba en el Liber de Predicatione coincideix del tot amb la que Dante posa en boca de Guido da Montefeltro i Folquet de Marsella. En el sermó que proposa pel diumenge vint-i-cinquè després de la Pentecosta, després de recordar per enèsima vegada que els musulmans són en possessió de Terra Santa, Ramon es queixa del fet que els cristians no volen fer res per evitar-ho, tot i que és a les seves mans recuperar-la guerrejant. ${ }^{8}$ I contrasta aquesta negligència amb l'estat de guerra permanent a l'interior de la cristiandat, on els cristians no paren de guerrejar entre ells, moguts per l'enveja, l'avarícia i la supèrbia. ${ }^{9}$ Llull segueix el seu sermó culpant els mals prínceps i els mals prelats que no exerceixen el poder que els permetria recuperar Terra Santa i es lamenta, just en el moment en què el col-legi de cardenals ha d'escollir un nou papa, que els prelats (i es refereix explícitament a un «mal Col-legi» i un «mal Capítol») no elegeixen els bons pastors que haurien de custodiar pacíficament les ovelles de Crist, sinó que escullen imprudentment i amb injúria llops rapaços que deixen que altres llops devorin les seves ovelles, quan no les devoren ells mateixos, i es preparen així un futur sense fi de penes infernals. ${ }^{10}$ No em sembla massa agosarat de pensar

5. «Lo principe d'i novi Farisei, / avendo guerra presso a Laterano, / e non con Saracin né con Giudei, // ché ciascun suo nimico era Cristiano, / e nessun era stato a vincer Acri / né mercatante in terra di Soldano" (Inferno, XXVII 85-90. Cito la Commedia seguint l'edició de Giorgio Petrocchi a Le opere di Dante Alighieri. Edizione Nazionale a cura della Società Dantesca Italiana, vol. IV, Florència: Le Lettere, 1994).

6. «In su la Terra Santa, / che poco tocca al papa la memoria. / La tua città, che di colui è pianta /che pria volse le spalle al suo fattore / e di cui è la 'nvidia tanto pianta, / produce e spande il maladetto fiore / c'ha disvïate le pecore e li agni, / però che fatto ha lupo del pastore» (Paradiso, IX 126-132).

7. L'obra és editada a ROL III i IV, 1961-1963.

8. ROL IV, 1963, p. 203.

9. «Sed unus fidelis contra alium fidelem cotidie ratione invidiae, avaritiae et superbiae movet bellum. Sed nullus vult bellare pro nomine Iesu Christi et pro ecclesia militante» (ibid.).

10. «Sic praelati, ut in pluribus, nullatenus eliguntur, quia non eliguntur boni pastores, qui deberent custodire pacifice oves Christi; sed lupi rapaces cum iniuria, imprudentia, etc. eliguntur, qui dimittunt oves suas a lupis asperis devorare; immo ipsimet devorant oves suas. 
que Ramon, quan es refereix al mal Col-legi i el mal Capítol, té en ment el col-legi de cardenals que va fer papa Bonifaci VIII (a qui alguns dels seus contemporanis, com acabem de veure, descrivien como un pastor convertit en llop) i els capítols dels frares menors que van escollir successivament com a generals de l'ordre a Matteo d'Acquasparta i a Giovanni da Morrovalle (que es van singularitzar per la seva persecució del corrent dels espirituals, amb què Llull sintonitzava).

Més endavant parlarem de nou dels pastors que esdevenen llops. Però ara hauríem de tornar a la vuitena fossa del cercle vuitè de l'infern, on, com hem vist, es troba Guido de Montefeltro. Cal recordar, d'entrada, que aquesta fossa, la mateixa en què Dante i Virgili ja havien topat amb Ulisses en el cant anterior, és la que està reservada als consellers fraudulents. Ulisses, tot i que en el seu parlament prefereixi parlar del desig de coneixement, hi és perquè, amb els seus consells enganyosos, com el referent a la construcció del famós cavall de fusta, va provocar la ruïna de Troia. ${ }^{11}$ Semblantment, Guido, tot i el seu llarguíssim historial militar com a enemic de l'Església, s'hi troba per un pecat comès després de la seva reconciliació amb el papat i d'haver optat per la vida religiosa. La seva condemna té a veure amb el pèrfid consell que, contra la seva resistència inicial, havia acabat donant a Bonifaci VIII, la bèstia negra de Dante, aquell a qui, com hem vist, Folquet de Marsella descriurà com un pastor convertit en llop més interessat a guerrejar contra altres cristians que en recuperar Terra Santa.

El papa, aleshores enfrontat amb els Colonna, li havia demanat assessorament quan els emissaris d'aquesta família l'havien anat a veure a Rieti per implorar misericòrdia. Guido només va accedir a donar el seu consell un cop que el sant pare, després de recordar-li que les claus que obren i tanquen el regne del cel eren seves, li va prometre l'absolució pel pecat que pogués cometre en donar-lo. El seu consell es va concretar en una elegant sentència: "Promesa llarga i curt compliment» (Lunga promessa con l'attender corto). ${ }^{12}$ Bonifaci en va fer bon cabal. Va prometre el perdó i la revocació de l'excomunicació als fins feia poc insubmisos i va convidar els emissaris a tornar tranquils a Palestrina assegurant-los que restituiria la ciutat a la família dels Colonna. Poc després el seu exèrcit va arrasar-la. Com va escriure el propi papa en una carta: "Es van tallar les vinyes i els arbres, es van devastar els conreus, es van saquejar els ramats, es van fer presos els habitants i se'ls va assassinar». ${ }^{13}$

Ah malum collegium, ah malum capitulum, qualiter excaecaris, quare malum praelatum eligis vitiose? Oh quid facis? A tactu tunicae Filii Dei turpiter elongas te, et tibi poenam praeparas infernalem, durabilem sine fine» (ibid., p. 203-204).

11. «E dentro da la lor fiamma si geme / l'agguato del caval che fé la porta / onde uscì de' Romani il gentil seme. / Piangevisi entro l'arte per che, morta, / Deïdamìa ancor si duol d'Achille, / e del Palladio pena vi si porta» (Inferno, XXVI 58-63).

12. Inferno, XXVII 111.

13. Citat a Guillaume de Thieulloy, Le pape et le roi. Anagni, 7 septembre 1303, París: Gallimard, 2010, p. 177. 
Dante s'ocupa dels consellers fraudulents en els cants 26 i 27 de l'Inferno. Llull, que va destinar integrament dues obres a l'art d'aconsellar en general, també va dedicar de manera més concreta un llibre al coneixement del mal consell: el setè del Llibre de meravelles, el Llibre de les bèsties, que, segons la ficció, Fèlix, el protagonista de la resta de l'obra, "portá ha un rey per tal que veés la manera segons la qual, en ço que fan les besties es significat com rey deja regnar e.s deja guardar de malvat consell e de falses homens». ${ }^{14}$

En el pròleg del Liber de consilio, escrit el març de 1304, uns mesos abans de Liber de praedicatione i que és la primera de les seves dues obres sobre l'art d'aconsellar en general, Ramon ofereix un diagnòstic de l'estat del món a inicis del segle xiv en què queda molt clar el lloc que li pertoca al consell en la seva concepció del govern. Segons el seu plantejament, són els poderosos, tant els prelats com els prínceps, els responsables de la mala situació del món. I ho són per dos motius: per la seva pròpia insensatesa i perquè reben mals consells dels seus assessors. ${ }^{15}$ Dante fa una anàlisi semblant al Convivio, on, després de defensar amb tons ciceronians que l'autoritat imperial i l'autoritat filosòfica han d'anar de la mà, acaba advertint a Carles de Nàpols i Frederic de Sicília, als que descriu com a "enemics de Déu», de les conseqüències nefastes d'escollir mals consellers. ${ }^{16}$ Dante i Llull no són gaire originals quan fan aquesta mena de diagnòstics. La qüestió de la relació entre el poder i el saber és una qüestió central en el pensament polític de l'Edat Mitjana, època en la qual, tot i que no es desconeix la figura platònica del rei filòsof, la figura del conseller acostuma a protagonitzar el tractament d'aquesta qüestió perquè se sol donar per bo que és per la seva mediació, d'acord amb el model ofert tòpicament per Aristòtil i Alexandre el Gran, que el saber s'uneix amb el poder que posseeixen els magnats. Aquesta és, si més no, la imatge que transmeten

14. Ramon LLuLL, Llibre de meravelles, vol. I, llibres I -VII, a NEORL X, 2011, p. 269. Les altres dues obres sobre l'art del consell són el Liber de consilio, compost a Montpeller el març de 1304 i editat a ROL X, 1982, p. 101-235, i l'Ars consilii, escrit a Tunis el juliol de 1315, dedicat al rei Abu Yahiya al-Lihyani i publicat a ROL II, 1960, p. 213-269.

15. "Quidam homo mirabatur de christianis, quare non magis exaltabantur super infideles, qui terras eorum acquirebant; et quare inter christianos auaritia, guerrae et alia peccata tantum uigebant. Quoniam uidebatur ei, quod propter hoc, quod fidem ueram et sanctam habent, infideles uero non, omnes alias nationes deberent suppeditare, et in magna caritate et aliis uirtutibus ad se inuicem permanere. Dum sic cogitabat, uidebatur ei, quod omnia ista essent propter defectum magnatum, uidelicet principum et praelatorum, eo quia maxime praui sunt, et malum consilium habent» (Liber de consilio, ROL X, 1982, p. 120).

16. "Oh miseri che al presente reggete! e oh miserissimi che retti siete! ché nulla filosofica autoritade si congiunge colli vostri reggimenti né per propio studio né per consiglio [...]. Ponetevi mente, nemici di Dio, a' fianchi, voi che le verghe de' reggimenti d'Italia prese avete - e dico a voi, Carlo e Federigo regi, e a voi altri principi e tiranni-guardate chi a lato vi siede per consiglio, e annumerate quante volte lo die questo fine dell'umana vita per li vostri consiglieri v'è additato! Meglio sarebbe a voi come rondine volare basso, che come nibbio altissime rote fare sopra le cose vilissime!» (DAnTe, Convivio, IV, 6, 19-20, Le opere di Dante Alighieri. Edizione Nazionale a cura della Società Dantesca Italiana vol. 2, tomi 3, ed. Franca Brambilla Ageno, Firenze: Le Lettere, 1995). Cfr. Ciceró, De inventione, I, 1. 
els miralls de príncep que, en ocasions traduïts de l'àrab o de l'hebreu, comencen a circular a partir del segle xiII per les corts de l'occident llatí. Com el Secret dels secrets, el Calila i Dimna o el Llibre del Sidrac, que mostren que els sobirans històrics o ficticis que simbolitzen el bon règim han arribat a simbolitzar-lo perquè han sabut associar els savis al seu govern. El Llibre de les bèsties, que Llull va escriure durant la seva primera estada a París, pels volts de 1287 , està profundament relacionat amb aquesta mena de literatura, particularment amb el Calila i Dimna. ${ }^{17}$ En aquesta intervenció em centraré bàsicament en aquesta obra lul.liana i miraré de mostrar que l'ensenyament que Llull hi vol transmetre no acaba de coincidir del tot amb aquella doctrina que ensenya els pastors a tenir cura de les seves ovelles.

\section{La força i el frau en el Llibre de les bèsties}

Ramon coneixia bé el Calila i Dimna. I el Llibre de les bèsties, que també és un mirall de prínceps, a més d'aprofitar molts dels seus exemples i esquemes narratius, incorpora no tan sols aquesta idea sobre l'important rol de la figura del conseller, sinó també allò essencial de la doctrina sobre el poder que pretenia transmetre. Aquesta doctrina es podria sintetitzar, d'entrada, com segueix. La força física, entesa com a capacitat d'exercir una violència que genera temor, és un atribut necessari del poder (és per aquesta raó que els animals que mengen carn consenten que el lleó sigui rei i és per la por a la força dels carnívors que els animals que mengen herba han d'acabar assumint el nou poder reial). ${ }^{18}$ Però aquesta força física, que, en principats de nova creació, pot permetre d'assolir el poder, no és suficient pel seu manteniment. En aquest respecte, la força d'una determinada mena de intel.ligència, l'astúcia, allò que Llull denomina maestria (que és una de les característiques que defineixen la guineu) li és clarament superior. El lleó, que és escollit rei per la seva força física, només aconsegueix consolidar-lo quan $\mathrm{Na}$ Renard, que volia trair-lo i posar un altre rei en el seu lloc, és superada en el camp que li és propi, el de l'astúcia o, si es prefereix, el de la força del coneixement relatiu a les trampes i els enganys.

La doctrina sobre la superioritat de l'astúcia respecte a la força és un ensenyament que el Llibre de les bèsties transmet de forma reiterada. I no és per casualitat que es tracta d'un tema omnipresent en el capítol central de l'obra. ${ }^{19}$ En aquest capítol, que narra com $\mathrm{Na}$ Renard va arribar a ser porter del rei, s'expliquen dues faules que hi fan referència. La primera, la del corb i la serp,

17. Cfr. E. J. Neugaard, «The Sources of the Folk Tales in Ramon Llull's "Llibre de les bèsties" ", Journal of American Folklore, n. 84 (Filadèlfia 1971), p. 333-337 i les notes d'Armand Llinarès, Raymond Lulle. Livre des bêtes. Version française du Xve siècle avec traduction moderne, introdution et notes, París: C. Klinsieck, 1964, i Antoni Bonner, Fèlix o el Llibre de meravelles, "Llibre setè: de les bèsties», en Obres selectes de Ramon Llull (1232-1316), vol. II, p. 125-162.

18. Llibre de meravelles, VII, 37 («De la elecció del rey»), ed. cit., p. 223-225.

19. Llibre de meravelles, VII, 40 («En qual manera Na renard fo porter del rey»), ed. cit., p. 234-244. 
prové del Calila i Dimna, on, després de narrar-la, Dimna explicita la seva lliçó dient que l'ha explicat per fer comprendre que amb l'astúcia es pot assolir el que no es pot aconseguir amb la força. En el Llibre de les bèsties, $\mathrm{Na}$ Renard, que està oferint al lleó el seus serveis i vol subratllar la seva competència en el terreny de l'enginy, l'explica amb el mateix objectiu. ${ }^{20} \mathrm{La}$ segona faula la narra un dels consellers reials, el gall, per assessorar el rei, que està força preocupat per un problema de política exterior, el de la possible amenaça d'una superpotència veïna, el regne dels humans. El gall proposa al lleó un exemple que pren la forma d'una disputa al.legòrica entre la força i la maestria que hauria tingut lloc davant d'un altre rei. La personificació de cadascun d'aquests dos conceptes defensava que, per naturalesa, li pertocava dominar sobre l'altra. Per dirimir la qüestió sobre a quina li corresponia naturalment manar, el rei les va fer combatre. I "Maestria — conclou el gall— vencé et sobrá Força». ${ }^{21}$

El gall posa aquest exemple per desaconsellar l'establiment relacions diplomàtiques amb el rei dels homes. La seva lliçó és que aquells que només combaten amb la força no tenen res a pelar amb aquells que fan ús tant de la força com de l'astúcia. I que, per això, el lleó cometria un error si pensés que es podria arribar a defensar amb l'astúcia d'un rei, el dels humans, que el supera en aquest terreny. Aquesta doctrina contrasta amb la que dóna tot seguit $\mathrm{Na}$ Renard, que ara, després d'afirmar que Déu mai no fa ús de l'astúcia, manté que, segons la naturalesa, s'escau que aquells que combaten amb armes semblants a les de Déu, siguin els més poderosos en les batalles. ${ }^{22} \mathrm{El}$ fet que sigui $\mathrm{Na}$ Renard, que espera satisfer la seva ambició únicament amb l'astúcia, la que, dissimulant allò que realment creu, defensa el domini de la força davant d'un lleó que ha esdevingut rei precisament perquè la mateixa guineu ha fet notar que representa aquesta força, posa de manifest l'habilitat literària de Llull.

La doctrina sobre la superioritat de l'astúcia respecte a la força té com a corol.lari, en el Llibre de les bèsties, la doctrina segons la qual només amb l'astúcia, que no tan sols pot posar trampes als que només són forts, sinó també usar a favor seu la força de tercers, es pot vèncer l'astúcia. El lleó s'acaba cruspint $\mathrm{Na}$ Renard, però el procés que porta a la derrota de la guineu segueix el pla marcat per consells de l'elefant. Així es pot veure en l'últim capítol del llibre, titulat «De la mort de $\mathrm{Na}$ Renard», en què Llull subratlla que l'elefant va dir-se que de la mateixa manera que la guineu volia matar amb astúcia el lleó, ell mataria també amb astúcia la guineu. Ramon té molt interès a deixar clar que l'elefant va pensar que si en el cos de la guineu hi cabien la traïció, la certesa i la maestria, en el seu, que era molt més gran, hi cabien no només la lleialtat i la

20. Ibid., p. 237-238. Cfr. Abdalá Benalmocaffa, Calila y Dimna, traducció de Marcelino Villegas, Madrid: Alianza Editorial, 2008, p. 125: «Te he contado esta fábula para que comprendas que la astucia consigue lo que no consigue la fuerza».

21. Ed. cit., p. 243

22. Ed. cit., p. 244 
saviesa, sinó també la mateixa maestria. ${ }^{23}$ Morta $\mathrm{Na}$ Renard, l'elefant serà escollit pel lleó com a conseller en lloc de la guineu i aquesta elecció coincidirà, no per atzar, amb el retorn de la cort al bon estament. Les tres qualitats que s'allotgen en el seu cos són les qualitats d'un bon conseller. La lleialtat n'és evidentment, segons Llull, una propietat indispensable, mentre que la traïció, que és el seu contrari, caracteritza el conseller malvat. La saviesa, que és un coneixement relatiu a la causa final i al bon ordre entre les intencions que s'hi ordenen, també és un tret propi del bon conseller. Llull la contrasta subtilment amb la certea que s'atribueix a Na Renard, que és una aptitud, oposada a la grossesa intel.lectual i pertanyent a l'àmbit de la intel-ligència pràctica, que permet d'assolir objectius, amb independència de la bondat o la maldat d'aquests objectius, i que no és, considerada en si mateixa, ni bona ni dolenta. ${ }^{24}$ A primer cop d'ull, pot semblar que resulta difícil de distingir aquesta certea del que Llull denomina maestria, que és una virtut que, segons el Llibre de les bèsties, com acabem de veure, poden compartir els bons i els mals consellers. Però en Llull, el concepte de maestria, que coincidiria amb allò que ara denominem astúcia, acostuma a anar associada a la idea d'engany. ${ }^{25}$ Per tant, és gràcies al fet que en el cos de l'elefant també hi cap, a més de la certesa, l'astúcia, una llestesa relativa a l'engany, un enginy ben equipat tant per enganyar com per no deixar-se enganyar, que el lleó pot retenir el poder derrotant la guineu, que també troba en l'astúcia una de les seves principals característiques. ${ }^{26}$ És important no perdre de vista la manera com al llarg del llibre Ramon va perfilant el caràcter del lleó i com destillla a través d'aques-

23. «Ell dix enfre si que enaxí com Na Renart ab maestria volia fer auçiure al rey, que anaxí ell ab maestria fes auçiure al Rey Na Renart. "Cor, si en lo cors de Na Renart cap traïció, çertea ni maestria, quant mes - dix l'Aurifany- en mon cor[s], qui es tan gran, deu caber lealtat, saviea et maestria”» (ed. cit., p. 265).

24. Libre de contemplació en Déu, cap. 76, 9, dins ORL III, 1906, p. 94: «car si l'ome pec fa neguna errada per peguea e per defalliment de certea, la vostra justicia [es refereix a la justícia divina] escusa aquell e no ponex aquell de greus penes; e si l'ome cert fa falliments per oltracuidament de saber, la vostra justicia punex aquell de greus penes e no reeb d'ell nulla escusa.» Aquesta aptitud intel.lectual no era considerada ni per Llull ni per la tradició exclusiva dels homes: "Les bèsties ... sempre que són nades an forsa e certea de percassar so d'on prenen vida» (ibid., cap. 103, 8, ORL IV, 1910, p. 4). Cfr. Aristòtil, Historia animalium, VIII, 1.

25. Cfr. Libre de contemplació en Déu, cap. 210, 22-24, ORL V, 1911, p. 358-359. Cfr. Arnau DE VILANova, Raonament d'Avinyó, en Obres catalanes, Barcelona: Barcino («Els Nostres Clàssics»), 1947, vol. I, p. 178-179: "Car, pus que.ls prelats e les crides no serven en vida ço que aquella Escriptura demostra, manifesta occasió donen, als prínceps e als altres, de pensar, duptan ea si ço que aquela Escriptura conté és veritat, o si és obra de Déus o d'òmens maestrejats».

26. A Ėtica a Nicòmac VI, 13 (1144a 23-7), Aristòtil distingeix entre l'aptitud intel-lectual que ens fa capaços de descobrir i usar els mitjans més eficaços per assolir qualsevol objectiu que ens proposem (que denomina deinotès), la prudència (phrónesis), terme que reserva a aquesta aptitud quan la meta que es persegueix és bona, i l'astúcia (panourgía), que seria el nom que rebria aquella aptitud quan la meta perseguida és dolenta. En el vocabulari lul.lià, la certesa es correspon amb la deinotès aristotèlica, que en llatí se solia traduir per industria, i la maestria amb la panourgía, que en llatí s'acostumava a traduir per astutia. 
ta caracterització les seves doctrines sobre el poder i sobre el govern. Com hem vist, és per la força que el defineix i per la por que desperta que arriba al poder. I és també per la força dels animals que mengen carn en general que els animals que mengen herba se senten obligats a assumir la seva reialesa. Un cop fet rei per la voluntat dels seus nous súbdits, el lleó no s'aparta del que es presenta com la llei natural: la seva primera decisió és permetre els animals que mengen carn i que han afavorit la seva elecció que es mengin els animals que mengen herba. ${ }^{27}$ Aquesta situació empeny a l'exili el cavall, que era el pretendent del herbívors a la corona, i el bou, que s'havia singularitzat com el principal defensor de la seva pretensió. Però les seves respectives experiències a l'exili els fan veure que és millor estar en perill de mort en la pròpia pàtria que en una d'aliena. ${ }^{28} \mathrm{Amb}$ el seu poder ja reconegut, arriba el moment que el lleó nomeni els seus consellers i demana la col-laboració de la cort. A l'hora de fer-ho, demostra, si més no, que sap una de les coses que ensenyaven els miralls dels prínceps: que al sobirà li pertoca governar els altres i a si mateix i que, donat que això és molt complicat, li cal comptar amb consellers savis i lleials, que són la garantia de la salvació del poble. ${ }^{29}$ Però és precisament l'elecció d'aquest consell, del que inicialment és exclosa $\mathrm{Na}$ Renard, el que origina les maquinacions de la guineu per enderrocar el lleó i posar l'elefant en el seu lloc. Aquestes estratagemes li permetran, primer, servir com a porter del rei i, després, esdevenir el seu únic conseller.

Llull no s'està de mostrar, mentre narra com es desenvolupa tot aquest procés de traïdoria, que el lleó té, d'una banda, una intel-ligència més aviat escassa i que, d'altra, també mostra una clara propensió a l'ira, a la intemperància i a la luxúria. I el fet és que, sense un bon conseller al costat, no només està indefens davant l'astúcia de Na Renard, sinó que, a més, cau, un darrera l'altre, en tots els vicis, fins que finalment, després d'assassinar amb perfídia el lleopard, perd el favor dels seus súbdits perquè no hi ha res més perillós que estar sotmès a un rei injuriós, aïrat i traïdor. ${ }^{30}$ Aquest assassinat, que embota la seva ànima fins al punt de convertir-lo en més obtús del que ja era i de perdre la facultat d'interpretar els exemples que, a tall de consells, li presenten els seus assessors, acaba de confirmar que el lleó és incapaç de governar-se a si mateix i, per tant, de governar els altres sense el suport d'un bon conseller. ${ }^{31}$

27. «Per la força del Ors et de les altres besties qui menugen carn, malgrat de les besties que menuguen erba, fo elet lo Leó a esser rey; lo qual Leó doná licencia a totes les besties qui menugen carn que menjassen et vivissen de les besties qui menugen erba» (ed. cit., p. 225).

28. Ed. cit, p. 225-226.

29. «Et cor sia gran cosa treball a rey governar si matex et son poble, per açó vos prech tuyt ensemps que.m donets consellers qui.m ajuden et qui.m consellen de tal manera que sia salvament de mi et de mon poble» ("Del consell del rey», ed. cit., p. 236).

30. «Tots quants foren en la plaça del rey foren despagats del falliment que.l rey havia fet et cascú desirá esser en senyoria d'altra rei, cor molt es perillosa cosa subjugació de poble qui sia sotmés a rey injuriós, irós, traydor» (ed. cit., p. 254 ).

31. "Lo Leó, depuix que fo en peccat et hac mort lo Leupart, no hac tanta de sobtilea ni de engin com d'abans havia et no entés ço que les paraules que la serpent hac dites significaven; e dix a la Serpent que li esposés les paraules, cor ell no les entenia» (ed. cit., p. 258). 
Com ja hem vist, només l'astúcia de l'elefant, a qui li sembla més sensat, si vol sobreviure, fiar-se del lleó que de la guineu, permet que el lleó mantingui el poder i sigui capaç, a través del seu consell, d'establir un bon govern.

\section{El domini i el govern}

Una de les peculiaritats del miralls de príncep musulmans radica en la distinció entre dues categories de conceptes relacionats amb els fenòmens polítics. D'una banda, aquells que remeten al poder pensat com a domini. D'altra, aquells que parlen del poder en tant que el seu exercici s'ordena teleològicament a un fi ètic col-lectiu que transcendeix les passions dels individus particulars. ${ }^{32}$ El final del Llibre de les bèsties, un obra que s'inspira en aquests miralls, podria portar a concloure que Llull confon la qüestió del domini i de la seva perpetuació amb la del govern i la seva justícia. Però la lectura atenta de l'obra prevé de caure en aquest error. ${ }^{33} \mathrm{Hi}$ ha en l'obra dos fils que, tot i que per l'embull en què es troben en la superfície del text es poden prendre per un de sol, cal distingir. El fil principal de l'obra tracta de la primera d'aquestes qüestions, del domini. Explica, com hem vist, que la corona pertany al lleó perquè el poder polític és naturalment l'expressió d'una força que, per mitjà del seu exercici efectiu o de la por, ha aconseguit d'obtenir la submissió. I ensenya que aquesta força, la de la violència física, pot ser vençuda per una altra força, la de l'astúcia, que només por ser derrotada per més astúcia o per l'aliança de la violència amb l'astúcia. D'acord amb aquest primer fil, el poder que triomfa a la fi de l'obra és un poder que es fonamenta en la força bruta i que aconsegueix imposar-se gràcies a l'associació a una altra força purament tècnica, la de la maestria, que li permet de no caure en els enganys dels enemics. Ramon deixa ben clar no només el motiu pel qual el lleó té el poder, sinó també que si l'acaba mantenint no és perquè l'exercici d'aquest poder sigui tingut per just pel seus súbdits. Com hem vist, el lleó que conserva el poder és un lleó que els seus súbdits consideren intemperant, injuriós i traïdor; una consideració que els fa desitjar ser súbdits d'un altre rei. La faula que explica Llull és, d'entrada, la faula d'un rei injust que acaba conservant el poder que havia obtingut gràcies a la por que despertava la seva força. I l'elefant, que acaba associant la maestria

32. Makram Aввѐs, Islam et politique à l'âge classique, París: Presses Universitaires de France, 2009 , p. 49.

33. L'última frase del llibre, l'anterior a l'explicit, és, llegida literalment, ambigua: «E pus que $\mathrm{Na}$ Renard fo mort, fo sa cort en bon estament. Lo rei feu de son consell l'Aurifany et el Senglar e d'altres honrats barons, et gitá.n lo Conill e lo Paó». La conjunció "pus que» pot tenir tant un sentit temporal (després que) com introduir la proposició que indica la causa suficient d'allò que es diu en l'altra proposició ( ja que). La meva interpretació és que Llull juga amb aquesta ambigüitat: la lectura superficial del text convida establir una relació causa-efecte entre la mort de la guineu i l'establiment del bon govern; la lectura profunda no accepta aquesta causalitat més aviat infantil i relaciona aquest establiment amb el nomenament d'un nou consell, amb barons astuts i honrats, de què es parla a l'última frase i que en seria la condició necessària. 
que comparteix amb la guineu a la força del lleó per tal de salvar-lo, ho fa, com es pot veure si es llegeix amb deteniment el text, més que per una lleialtat visceralment sentida cap al seu «senyor natural», perquè calcula que l'obediència li pot garantir millor la supervivència que la traïció. ${ }^{34} \mathrm{El}$ fet que aquesta calculada lleialtat acabi donant lloc a una situació en què impera el bon govern no sembla que es pugui atribuir a allò que s'explica: el triomf de l'astúcia de l'elefant sobre l'astúcia de la guineu.

L'altre fil, l'altra qüestió, la del govern i la seva justícia o injustícia, també es va deixant veure al llarg de l'obra. Hi irromp, sobretot, a través dels consells que els membres de la cort ofereixen al lleó per mitjà de la narració de faules i exempla. Una idea recorrent en aquests consells és que el rei ha d'imitar en el seu govern el govern de Déu en el món, un govern que s'expressaria tant a través de la llei natural com per mitjà de les autoritats i exemples bíblics. ${ }^{35}$ Ramon posa la majoria d'aquests consells en boca de Na Renard, que en ocasions cita l'autoritat de la Bíblia per fonamentar els consells fraudulents que ofereix al rei. ${ }^{36}$ És important d'assenyalar que no hi ha cap personatge a l'obra que es mostri tant preocupat pel bon regiment del nou regne com Na Renard. No n'hi cap que l'iguali donant consells simuladament pietosos al rei, quan el monarca és present, o criticant el mal govern del rei i els mals consells dels seus consellers, quan no hi són ni l'un ni els altres. Llull es complau a explicar com la guineu para les seves trampes per mitjà d'aquestes mostres de preocupació i d'aquestes crítiques. Un dels primers a caure-hi és el bou, recentment tornat de l'exili, que després de sentir-les narra un exemple que conclou la lliçó que, si el règim de lleó és tal com el descriu la guineu (és a dir: un règim malvat, amb un rei i un consell malvats), és millor estar amb els pastors que guarden les ovelles dels llops que amb el pastor que mata les seves ovelles i les dóna als

34. Ed. cit., p. 265. Llull descriu el procés que porta l'elefant a la decisió de ser fidel al seu senyor natural com un procés llarg. En un principi, pensa a consentir la mort del rei; finalment canvia d'opinió. Quan es planteja la traïció, té molt present que si no fa cas a $\mathrm{Na}$ Renard, que li proposa de participar en la conspiració, la guineu pot afavorir, com a consellera del rei, que el lleó el condemni a mort (per la seva predisposició anterior a trair-lo). Però en la deliberació que el porta a optar per la lleialtat al rei, hi és ben present la idea que, en cas d'acceptar la corona que li ofereix $\mathrm{Na}$ Renard, aquesta el pot acabar traint de la mateixa manera que al lleó. Certament, el text diu que l'elefant «amá mes estar en perill de mort, que fer traçió a son senyor natural», però cal no oblidar que al darrere d'aquesta preferència hi ha la consciència del fet que, mentre Na Renard sigui viva, l'elefant, faci el que faci, estarà en perill.

35. Cfr. Michel Senellart, Les arts de gouverner. Du regimen médiéval au concept de gouvernement, París: Éditions du Seuil, 1995, p. 200.

36. Ja en la seva primera intervenció en el llibre, realitzada en el moment de la deliberació prèvia a l'elecció del rei, Na Renard, després de recordar la intenció amb què Déu ha creat el món, aconsella a les bèsties reunides en assemblea que segueixin la llei natural: «devets seguir la retgla e l'ordenança que Deus ha donada e posada en les creatures» (ed. cit., 223224). En el capítol "En qual manera Na Renart fo porter del rey», es troba un d'aquests consells fonamentats en l'autoritat de la Bíblia: la guineu aconsella el rei que es desfaci d'un dels seus primers consellers, la serp, recordant la maledicció divina que pesava sobre aquest rèptil per haver mal aconsellat Eva en el Paradís (ed. cit, p. 239). Cfr. Gènesi 3, 14-15. 
llops. ${ }^{37}$ És l'única aparició de la metàfora pastoral del govern en el Llibre de les bèsties. I cal tenir molt en compte quina és la seva funció en la trama. Ramon fa que el bou, empassant-se ingènuament l'ham que li posa la guineu, assumeixi que la imatge tòpica del mal govern descriu amb fidelitat la situació del regne. Aquesta assumpció, convenientment manipulada per $\mathrm{Na}$ Renard, és la condició de possibilitat de l'estratègia de la guineu, que té previst de servir-se del bou com a esquer per atrapar la voluntat del lleó.

Posant-lo en boca o al servei de $\mathrm{Na}$ Renard, Llull apunta tàcitament que el discurs sobre el bon govern (i també el que pretén basar-se en la llei natural) pot no ser un discurs innocent $\mathrm{i}$ ben intencionat i que aquells que hi recorren, sovint amb èxit, ho poden fer, com la guineu, no realment preocupats pel bé comú, sinó moguts pel seu interès particular. Convé no oblidar, en efecte, que, en el Llibre de les bèsties, com en tantes altres faules, la guineu no només simbolitza l'astúcia. A més de la maestria, de la qual forma part l'art enganyós de la dissimulació i de la simulació, la caracteritza un dels vicis característics d'aquesta art, la hipocresia (els practicants de la qual també tenen una fossa reservada, la sisena, al cercle vuitè de l'Inferno dantesc). $\mathrm{Na}$ Renard simula amb les seves paraules la santedat i dissimula així la intenció perversa que la caracteritza. En un dels sermons del Liber de praedicatione, Llull compararà anys després, en una comparació que fa explícita la seva manera d'entendre el simbolisme de la guineu, els falsos religiosos amb aquest animal. Els falsos religiosos, dirà aleshores, són com la guineu, com l'hipòcrita, que es mostra com a sant en el seu rostre i en el seu hàbit, que es presenta sota l'aparença d'eremita, però que amaga tàcitament una serp verinosa en el seu cap. ${ }^{38}$ I en el mateix sermó, després d'apuntar que l'Evangeli de Mateu parla contra aquests falsos religiosos anomenant-los fariseus hipòcrites, els descriurà com a llops rapaços. ${ }^{39}$

Com hem vist, Llull va escriure aquest sermó els mateixos anys en què Dante feia que Folquet de Marsella comparés Bonifaci VIII, a qui Guido da Monteferro descriu com el príncep dels fariseus, amb un pastor convertit en llop. La coincidència entre Dante i Llull pel que fa a la seva valoració de la situació de la cristiandat a principi del segle XIV queda ben il.lustrada en aquestes coincidències. En qualsevol cas, el Llibre de les bèsties i el Llibre de meravelles de què forma part són força anteriors a aquests anys. En el Llibre de meravelles, justament en el començament del llibre vuitè, que és el que ve a continuació del Llibre de les bèsties, Llull encara no compara els pastors eclesiàstics amb llops rapaços. El seu ús de la metàfora pastoral del govern és més

37. «Et dix que mellor cosa era estar ab los pastors qui guardaven les besties dels lops que ab pastor qui les sues ovelles auciu et dona als lops» (ed. cit., p. 235).

38. «Falsus religiosus est in bonis Dei sicut vulpes, sicut hypocrita, qui in habitu et vultu ostendit se sanctum, et apparet in faci eremita; sed latet serpens in su mente tacita venenosus. In suis tamen operibus potest eius falsitas verius apparere» (ROL IV, 1963, p. 37).

39. "Et quae utilitas est hypocritis, quod appareant sancti in habitu et in vultu, et hoc cum labore, ieiunando, loquendo humiliter, et orando; et intus sunt lupi rapaces» (ibid.). 
suau. El papa, els cardenals i els prelat només són comparats per Fèlix, el protagonista de la novel.la, amb mals pastors que no fan cas dels gossos, que serien els cristians que viuen prop dels infidels i que borden infructuosament perquè els pastors facin el que pel seu ofici els pertoca: combatre els errors dels no cristians. ${ }^{40}$

Cal remarcar, pel que fa a aquest últim ús de la metàfora pastoral, la coincidència entre la descripció que el bou, en el Llibre de les bèsties, fa, caient en la trampa de la guineu, del mal regiment del poder reial del lleó i la descripció que Fèlix realitza, en el llibre següent, que ja no tracta de les bèsties sinó de l'home, del mal regiment de la cristiandat per part del poder eclesiàstic del papa, els cardenals i els prelats. Fèlix que, assistint als fets ficticis que s'expliquen en el Llibre de les bèsties, ha après que hi ha súbdits astuts que poden afavorir amb les seves insídies i enganys el sorgiment del discurs sobre el pastor convertit en llop per buscar l'animadversió cap els reis, sembla que no dubta, sabent el que ja havia après sobre Déu i sobre allò que li és degut en el llibre primer de l'obra, a qui li correspon la principal responsabilitat del mal regiment del món. Però cal remarcar també que, tot i que el seu diagnòstic sembla que és l'encertat als ulls de Llull, Fèlix en el Llibre de les bèsties ha après més coses sobre la manera de no caure en els enganys que sobre allò que faria bo un govern, tret del fet que aquest govern té, entre les seves condicions de possibilitat, que el rei sàpiga governar-se a si mateix $\mathrm{i}$, sobretot, que tingui al seu costat un bon conseller. En un bon règim, hi hauria de governar la justícia i aquest llibre, el setè del Llibre de meravelles, en què es tracta sobretot de la força i el frau, només parla de la justícia per descriure allò que cau fora de la narració, el règim que sorgirà de l'aliança de la força del rei no amb aquesta astúcia, no amb el coneixement purament tècnic relatiu als mitjans, sinó amb la saviesa en relació al fins que també hauria de caracteritzar el bon conseller.

\section{La força i el frau polítics en la tradició literària}

La força i el frau formen una parella de conceptes que ha interpretat un paper més important al llarg de la història del pensament polític del que se sol pensar en l'actualitat. Ciceró ja en parla al De officiis, posant-los en relació precisament amb la justícia. Hi diu que hi ha dues maneres de cometre la injustícia, amb la força i amb el frau, i fent comparèixer les dues bèsties que protagonitzen la faula lul.liana, afirma que la primera sembla pròpia del lleó i la segona de la guineu. I, a continuació, afegeix que totes dues són summament alienes als homes, tot i que el frau és més odiós perquè no hi ha injustícia pitjor que la d'aquells que quan la cometen simulen ser homes de bé. ${ }^{41}$ Poc abans, en

40. Ramon Llull, Llibre de meravelles, ed. a cura de Salvador Galmés, Barcelona: Barcino («Els Nostres Clàssics»), 1933, vol. III, p. 5-6.

41. "Ac de bellicis quidem officiis satis dictum est. Meminerimus autem etiam adversus infimos iustitiam esse servandam. Est autem infima condicio et fortuna servorum, quibus non male praecipiunt, qui ita iubent uti, ut mercennariis: operam exigendam, iusta praebenda. Cum 
aquesta mateixa obra, havia afirmat que hi ha dues maneres d'acabar una guerra, amb la força i amb la negociació i que, tot i que aquesta última era la pròpia dels homes, a vegades era precís recórrer a la primera, que és la pròpia de les bèsties. ${ }^{42}$ La Rhetorica ad Herennium, que els medievals també tenien per una obra de Ciceró, també s'ocupa d'aquests dos conceptes, precisament quan tracta del consell. Quan parla de gènere deliberatiu i concretament de les deliberacions polítiques, l'obra manté que s'escau que el conseller miri (com veiem abans que va fer l'elefant lul.lià) només per l'interès (la utilitas) i, en un gir curiós, divideix aquest interès en dues parts: la honestedat i la seguretat, que, al seu torn, es dividiria en la força i en el frau (vim et dolum). ${ }^{43}$ L'autor de la Rhetorica ad Herennium té clar que, a vegades, la seguretat (que es garanteix amb l'ús de la força i del frau) no concorda amb l'honestedat, amb allò virtuós, i aconsella, en aquests casos, redescriure l'acció que es recomana per fer-la aparèixer com a virtuosa (dient, per exemple, que, en una determinada situació, és propi de valents fer allò que, en una altra, seria un signe de covardia). ${ }^{44}$ Com es pot veure, aquesta posició concorda, en allò essencial, amb el passatge de la molt citada "Epistola dedicatòria» del De cive, en què Hobbes

autem duobus modis, id est aut vi aut fraude, fiat iniuria, fraus quasi vulpeculae, vis leonis videtur; utrumque homine alienissimum, sed fraus odio digna maiore. Totius autem iniustitiae nulla capitalior quam eorum, qui tum, cum maxime fallunt, id agunt, ut viri boni esse videantur. De iustitia satis dictum» (Ciceró, De officiis, I, 12, 41, ed. i trad.Walter Miller, Loeb Classical Library, Cambridge: Harvard University Press, 1913, p. 44-46, cursiva meva).

42. «Sunt autem quaedam officia etiam adversus eos servanda, a quibus iniuriam acceperis. Est enim ulciscendi et puniendi modus; atque haud scio an satis sit eum, qui lacessierit iniuriae suae paenitere, ut et ipse ne quid tale posthac et ceteri sint ad iniuriam tardiores. Atque in re publica maxime conservanda sunt iura belli. Nam cum sint duo genera decertandi, unum per disceptationem, alterum per vim, cumque illud proprium sit hominis, hoc beluarum, confugiendum est ad posterius, si uti non licet superiore» (Ciceró, De officiis, I, 11, 34, ed. cit., p. 34-36, cursiva meva).

43. «Omnem orationem eorum, qui sententiam dicent, finem sibi conveniet utilitatis proponere, ut omnis eorum ad eam totius orationis ratio conferatur. Utilitas in duas partes in civili consultatione dividitur: tutam, honestam. Tuta est, quae conficit instantis aut consequentis periculi vitationem qualibet ratione. Haec tribuitur in vim et dolum, quorum <aut $>$ alterum separatim aut utrumque sumemus coniuncte. Vis decernitur per exercitus, classes, arma, tormenta, evocationes hominum et alias huiusmodi res. Dolus consumitur in pecunia, pollicitatione, dissimulatione, maturatione, mentitione et ceteris rebus de quibus magis idoneo tempore loquemur, si quando de re militari aut de administratione re <publica $>$ scribere velimus. Honesta res dividitur in rectum et laudabile [...]» (Rhetorica ad Herennium, III, 2, 3, ed. i trad. H. Caplan, Loeb Classical Library, Londres-Cambridge. Mass.: Heinemann i Harvard University Press, 1954, p. 160-162, cursiva meva).

44. Rhetorica ad Herennium, III, 3, 6. Cfr. ibid. III, 5, 8: «honestum nihil oportere existimari, quod non salutem pariat». Quintil.lià fa un sugeriment que apunta en la mateixa direcció a Institutio oratoria, III, 8, 31: «Sed neque hic plane concedendum est esse id inhonestum» i III,8, 32: "Haec autem, quae tantum inter se pugnant, plerumque nominibus deflecti solent». Per aquesta qüestió en general, Maurizio Viroli, Machiavelli’s God, Princeton, New Jersey: Princeton University Press, p. 129-131. Per la qüestió més concreta de les tècniques de redescripció, Quentin SkInner, Reason and Rhetoric in the Philosophy of Hobbes, Cambridge: Cambridge University Press, 1996, p. 138-180. 
afirma, segles després, que a vegades els homes de bé, a causa de la depravació dels malvats, han de recórrer a les virtuts guerreres de la força i el frau, és a dir, a la rapacitat de les bèsties (ad ferinam rapacitatem)..$^{45}$

La tradició literària al seu abast ensenyava als medievals que la força i el frau, propis de les bèsties i en concret, respectivament, del lleó i de la guineu, eren causes d'injustícia. Però també que, en cas de necessitat, quan la seguretat ho exigia, calia recórrer, en l'activitat política, a la bestialitat. Dante va tenir ben present la primera d'aquestes dues lliçons quan, a l'hora de donar raó de la geografia del seu Infern va identificar la força i el frau amb les dues causes de la injustícia en què radica el mal que el cel castiga i va usar la distinció entre aquests conceptes com el principal criteri de demarcació entre els seus territoris (tot i que se singularitzés fent del frau, a diferència de la força, un mal propi dels homes i per aquesta raó, i no per la suggerida per Ciceró, més condemnable). ${ }^{46}$ Pel que fa a Llull, tot s'esdevé com si hagués tingut presents les dues lliçons tradicionals quan va decidir que volia oferir al seu príncep algunes doctrines sobre la força $i$ el frau en la seva enciclopèdia novel-lada i va optar per oferir-les, precisament, en la part que tractava dels animals.

La literatura secundària apunta que el Llibre de les bèsties, amb una faula animalística que actua com a narració marc d'altres faules o exemples, és un cos estrany en el context de la novel.la en què es troba inserida, una novel.la enciclopèdica en què un personatge, Fèlix, aprèn, a través del seu diàleg amb filòsofs i ermitans, una sèrie de doctrines referents a l'àmbit concret de la realitat de què tracta cada capítol. ${ }^{47}$ Aquesta remarca fa pensar en l'estranyesa amb què també solen rebre els estudiosos contemporanis una obra en aparença tan híbrida com els Livres du roy Modus et de la reine Ratio, que comença parlant de les diverses menes de cacera i que s'acaba despenjant també amb una faula de feres. O la inclusió dins de les Moralia de Plutarc del tractat sobre la intel-ligència dels animals (De sollertia animalium). Però, vist en el context literari que acabo de descriure, aquesta estranyesa desapareix. Llull hauria volgut ensenyar, recorrent a la faula, i en concret a aquella mena de faula en què es fa parlar els animals, aquella part de la política dels humans que és pròpia

45. «Profecto utrumque vere dictum est, homo homini deus, et homo homini lupus. Illud si convices inter se, hoc, si civitates comparemus. Illic justitia et claritate virtutibus pacis ad similitudinem Dei acceditur; hic propter malorum pravitatem recurrendum etiam bonis est, si se tueri volunt, ad virtutes bellicas, vim et dolum, id est ad ferinam rapacitatem» (Thomas НоввеS, De cive [1642], "Epistola dedicatoria», la segona cursiva és meva), dins Opera latina II (1839), p. 136.

46. "Figliuol mio, dentro da cotesti sassi”, / cominciò poi a dir, "son tre cerchietti di grado in grado, come que' che lassi. // Tutti son pien di spirti maladetti; / ma perche/ poi ti basti pur la vista, / intendi come e perche/ son costretti. // D'ogne malizia, ch'odio in cielo acquista, / ingiuria èll fine, ed ogne fin cotale / o con forza o con frode altrui contrista. // Ma perche/ frode è de l'uom proprio male, / più spiace a Dio; e però stan di sotto / li frodolenti, e più dolor li assale. // Di violenti il primo cerchio è tutto [...]» (Inferno XI, 16-28, cursiva meva). Cfr. supra Ciceró, De officiis, I, 41.

47. Anthony Bonner i Lola Badia, Ramon Llull. Vida, pensament i obra literària, Barcelona: Empúries, 1988, p. 137-138. 
de les bèsties i que, segons els antics, es podia aprendre observant els comportaments dels propis animals i prenent nota de les seves habilitats per mitjà de la pràctica de la caça i la pesca. Potser no és ociós de recordar, un cop arribats a aquest punt, que de la guineu i del lleó, també en parla Guido da Montefeltro en la seva confessió a Dante i a Virgili, quan, descrivint les seves accions, afirma, subratllant tàcitament la seva major condemnabilitat segons la tradició ciceroniana, que no eren les pròpies del lleó, sinó les de la guineu. ${ }^{48} \mathrm{Ni}$ d'apuntar també, encara que només sigui de passada, que Benvenuto d'Imola, en el seu comentari a la Commedia, interpreta el que diu Guido da Montefeltro, quan descriu amb voluntat d'excusar-se la situació que va desencadenar l'acció que l'hauria portat a l'infern, com si hagués volgut dir que, tot i ser ell mateix molt astut, Bonifaci, que n'era encara més, l'havia enganyat amb les seves paraules sobre el poder de les claus. ${ }^{49}$ Guido s'autodefineix com una guineu que excel-lia en l'art de l'engany i que va ser enganyat per algú per parava millor que ell les trampes. I Dante li reserva un lloc a l'infern entre els consellers fraudulents perquè, fent com si cregués que el frau que proposava ja havia estat absolt per Bonifaci, va tirar pel dret afavorint deshonestament un comportament injust.

La qüestió que s'amaga sota la closca del que Dante i Virgili van poder sentir a la vuitena fossa del cercle vuitè de l'Infern és també, de fet, la qüestió d'una determinada mena de mentida política i de la seva legitimitat i, més concretament, la de la responsabilitat dels consellers en el seu ús per part dels prínceps. És, com es pot veure, una qüestió molt relacionada amb la que es tracta en el famós capítol 18 d'El Príncep de Maquiavel, un capítol en què el secretari florentí va tenir molt en compte, segons alguns erudits, el cant 27 de l'Inferno en què apareix Guido. Aquest capítol porta com a títol «De quina manera els prínceps han de mantenir la paraula donada»(Quomodo fides a principibus sit servanda). I Maquiavel hi defensa que el Príncep ha de saber unir la força del lleó (per esporuguir el llops) amb l'astúcia de la guineu (per conèixer les trampes). ${ }^{50} \mathrm{Ja}$ sabem on havia portat Guido, segons Dante, el consell que havia donat a Bonifaci VIII de no mantenir la seva promesa.

48. "Mentre ch'io forma fui d'ossa e di polpe / che la madre mi diè, l'opere mie Inon furon leonine, ma di volpe» (Inferno, XXVI 73-75, cursiva meva).

49. "Là 've 'l tacer mi fu avviso il peggio, scilicet", ad satisfaciendum voluntati, quia malum videbatur mihi respondere, sed peius tacere; quasi dicat: Bonifacius astutissimus circumvenit me astutissimum verbis suis, quia non poteram ulterius honeste vel tute me excusare, quia nolebam negare potestatem summi pontificis, qui dicitur Deus in terris, aut eius scientiam et prudentiam magnam. Et sic comes, dum nititur se excusare, accusat [...]» (Benvenuto DA Imola, Comentum super Dantis Alighieris Comoediam, Inferno, XVII, vv. 106-111, Biblioteca Italiana, Università degli Studi di Roma La Sapienza, cursiva meva).

50. «Sendo dunque necessitato uno principe sapere bene usare la bestia, debbe di quelle pigliare la golpe e il lione: perché el lione non si difende da' lacci, la golpe non si difende da' lupi; bisogna adunque essere golpe a conoscere e' lacci, e lione a sbigottire e' lupi» (Niccolò MACHIAVELLI, Il Principe, cap. 18, ed. Giorgio Inglese, Torino: Einaudi, 1995; versió electrònica: Roma: Biblioteca Italiana, 2003). 
Maquiavel, per la seva banda, subratlla que, sens dubte, és d'allò més lloable que un príncep mantingui la paraula donada i visqui amb integritat, però no s'està de dir, esbotzant la sortida d'emergència que havien instal.lat Ciceró i la Rhetorica ad Herennium, que els qui se'n surten millor són aquells que, quan els ha convingut i seguint la manera de la guineu, s'han saltat aquesta observança. ${ }^{51}$ Per bé que podria haver esmentat l'exemple de Bonifaci VIII, Maquiavel opta per posar un exemple més proper, el d'un altre papa, Alexandre VI, un mestre en l'art de simular i dissimular, al qui considera incomparable en la pràctica d'enganyar els homes i de no respectar gens les promeses. ${ }^{52}$

\section{Faules animalístiques i realisme polític}

Si m'ha interessat introduir aquest capítol d'El Princep no és només, però, per recordar els ensenyaments que vol aportar a aquells que volen governar, sinó també, i sobretot, per allò que ensenya als estudiosos de la història de les idees i de les maneres de comunicar-les. Com potser algú recordi, aquest capítol d' $E l$ Príncep també incorpora una interessant lectura al-legòrica dels mites referents al centaure Quiró, que va portar damunt la seva gropa, mentre els ensinistrava de nens en les arts que els serien després indispensables (inclosa, evidentment, la de la caça), Aquil.les, Teseu, Heracles i d'altres prínceps antics. Segons Maquiavel, «el fet de tenir per preceptor un ésser meitat bèstia meitat home no vol dir altra cosa que al príncep li cal saber utilitzar l'una i l'altra naturalesa, ja que l'una sense l'altra no pot durar». ${ }^{53}$ Poc abans d'oferir aquesta clau hermenèutica, ha distingit, seguint tàcitament Ciceró, dues formes de combatre: l'una amb les lleis (que seria la pròpia de l'home) i l'altra amb la força

51. "Coloro che stanno semplicemente in sul lione, non se ne intendono. Non può pertanto uno signore prudente, né debbe, osservare la fede quando tale osservanzia gli torni contro e che sono spente le cagioni che la feciono promettere. E se li uomini fussino tutti buoni, questo precetto non sarebbe buono: ma perché e' sono tristi e non la osserverebbono a te, tu etiam non l'hai a osservare a loro; né mai a uno principe mancorno cagioni legittime di colorire la inosservanzia. Di questo se ne potrebbe dare infiniti esempli moderni e mostrare quante pace, quante promisse sono state fatte irrite e vane per la infidelità de' principi: e quello che ha saputo meglio usare la golpe, è meglio capitato" (ibid.).

52. «Ma è necessario questa natura saperla bene colorire ed essere gran simulatore e dissimulatore: e sono tanto semplici gli uomini, e tanto ubbidiscono alle necessità presenti, che colui che inganna troverrà sempre chi si lascerà ingannare.

Io non voglio delli esempli freschi tacerne uno. Alessandro sesto non fece mai altro, non pensò mai ad altro che a ingannare uomini, e sempre trovò subietto da poterlo fare: e non fu mai uomo che avessi maggiore efficacia in asseverare, e con maggiori iuramenti affermassi una cosa, che la osservassi meno; nondimeno sempre gli succederno gl'inganni ad votum, perché conosceva bene questa parte del mondo» (ibid.).

53. «Pertanto a uno principe è necessario sapere bene usare la bestia e lo uomo. Questa parte è suta insegnata alli principi copertamente da li antichi scrittori, e' quali scrivono come Achille e molti altri di quelli principi antichi furno dati a nutrire a Chirone centauro, che sotto la sua disciplina li custodissi. Il che non vuole dire altro, avere per precettore uno mezzo bestia e mezzo uomo, se non che bisogna a uno principe sapere usare l'una e l'altra natura: e l'una sanza l'altra non è durabile» (ibid.). 
(que seria la pròpia de les bèsties) i ha afirmat que, com que sovint no n'hi ha prou amb la primera, convé aleshores recórrer a la segona. És aleshores que Maquiavel afirma que el príncep té, per aquest motiu, la necessitat de saber fer com les bèsties i, molt en concret, com la guineu i el lleó. ${ }^{54}$

Tot això té molt a veure amb el que vèiem fa una estona a propòsit del Llibre de meravellles, que, en el llibre que dedica a les bèsties, usa els animals per instruir el príncep sobre les qüestions relatives a la força i el frau, és a dir, com hem vist, a allò que, segons una vella tradició que Dante modifica, constitueix la part animal de la política. Interpretat des d'aquesta tradició, el capítol 18 d'El Príncep, després de la seva lliçó explícita sobre com cal llegir les faules que parlen de prínceps instruïts per centaures, també ofereix de biaix una doctrina sobre una altra mena de faules del passat, les animalístiques. Si més no, sobre algunes de les faules d'aquesta mena que es presenten com a miralls del príncep i que, per tant, tenen la funció de transmetre literàriament l'ensenyament que el centaure Quiró oferia als seus deixebles. Calila i Dimna i el Panxatranta, que és la seva font llunyana, són les més famoses en la tradició oriental. I el Llibre de les bèsties, que usa generosament però també amb molt bon criteri el Calila i Dimna, és, segurament, l'exemple més reeixit d'aquesta literatura en la tradició llatina. Es precisament en la mesura que, com diu Maquiavel, el príncep té la necessitat de saber fer com les bèsties que aquestes faules li serveixen de mirall. Al segle XVII, el canonge Louis Machon va subratllar amb certa ironia però no sense pertinència, a la seva Apologie pour Machiavel, la poca novetat que implica la formulació en El Príncep de la màxima sobre el lleó i la guineu. I va recordar, entre altres coses, que tant la mateixa naturalesa, a través dels animals, com les faules, en què a vegades es fa parlar aquests animals, ensenyen allò que enuncia. ${ }^{55}$ Fixant-se sobretot en el Calila i Dimna, Makram Abbès ha assenyalat que el gènere dels miralls del príncep orientals es caracteritza, si es compara amb els miralls de príncep de la tradició occidental, pel seu realisme polític i pel seu pragmatisme i que, a

54. «Dovete adunque sapere come e' sono dua generazioni di combattere: l'uno, con le leggi; l'altro, con la forza. Quel primo è proprio dello uomo; quel secondo, delle bestie. Ma perché el primo molte volte non basta, conviene ricorrere al secondo » (ibid.). Cal subratllar que, d'acord amb el plantejament del secretari florentí, aquestes dues bèsties encarnen no només dues maneres de portar a terme la part animal de la política, sinó també dues maneres de combatre per mitjà de la força (una força el recurs a la qual defineix, precisament, segons ell, aquesta part animal de la política).

55. "Les enfants apprennent plutôt cette leçon, que la connaissance d'eux-mêmes, ni que les moyens de la bien pratiquer. Les politiques les moins entendus et les moins raffinés en font le fondement et la règle générale de leur prudence civil; les vieilles en amusent leurs petits, et les fables ne sont pas complètes, si celle-ci n'est du nombre». Com glosa Jean-Pierre Cavaillé en un estudi on reprodueix aquest passatge de l'Apologie pour Machiavel, segons Machon, "Machiavel ne fait rien d'autre que de tirer les enseignements politiques de ce qui disent toutes les fables, et de ce que les enfants apprennent avant tout autre chose de la nature même». Cfr. Jean-Pierre Cavaillé, «Louis Machon, les impostures du martyr d'État», en Dis/simulations. Religion, morale et politique au XVII siècle, París: Honoré Champion Éditeur, 2002, p. 314. 
més, presenta molts trets en comú amb l'esperit que anima autors antics com Tucídides i moderns com Maquiavel. ${ }^{56} \mathrm{I}$ ja fa anys que la bibliografia insisteix en el caràcter maquiavèl.lic avant la lettre dels consells del Panxatranta, sobretot dels referents a la política i el govern. ${ }^{57}$ Abbès té força raó pel que fa als miralls del príncep orientals i occidentals, sobretot si es compara llibres com el Calila i Dimna amb tractats de pedagogia principesca com els de Vicent de Beauvais o Egidi Romà, que s'ocupen, principalment, del bon govern i tendeixen a deixar de banda la qüestió del domini interpretada en clau naturalista. Però cal no oblidar que, en les corts occidentals, també hi ha un lloc (per bé que discutit des de la filosofia política d'arrel platònica que troba el seu reflex a Macrobi, que prefereix unes altres mentides polítiques més nobles) ${ }^{58}$ per a les faules isòpiques, que, tot i el procés de progressiva moralització a què són sotmeses, solen oferir, com va assenyalar Nøjgaard, lliçons d'un realisme inequívoc en el tractament de l'esquema bàsic que les caracteritza, un esquema que es defineix per les relacions antagòniques entre la força i la feblesa física d'una banda i la força i la feblesa intel-lectual per l'altra. Nøjgaard constata que, en aquestes faules, quan el conflicte es manté en el terreny d'allò físic, el fort sempre acaba vencent el feble (com en el cas de la faula del llop i l'ovella), mentre que quan el conflicte es desplaça al terreny intel.lectual la força de l'astúcia s'acaba imposant a la força bruta (com s'esdevé en el cas de la faula del llop pescador i el lleó, en què la guineu s'acaba imposant al llop). ${ }^{59}$ Es podria plantejar la hipòtesi que, pel que fa a la literatura dedicada a la formació dels prínceps, la tradició occidental va optar per una divisió de treball força escrupolosa d'acord amb la qual determinades obres (les faules de bèsties) s'ocupaven del que Maquiavel denomina «la veritat efectiva de les coses», és a dir, del coneixement de la manera en què se sol viure, mentre d'altres (els regiments de prínceps) es dedicaven a parlar de les coses com haurien de ser si els homes visquessin com ho haurien de fer.

En el Llibre de les bèsties es troba un bon repertori d'injustícies fetes o intentades tant per mitjà de la violència com per mitjà del frau. Com vèiem abans, Maquiavel manté en el capítol 18 d'El Príncep que, quan un és lleó, cal

56. Makram AвBغ̀s, op. cit., 2009, p. 19-23.

57. Franklin Edgerton, De Panchatantra Reconstructed, II: Introduction and Translation, New Haven: American Oriental Series 3, 1924, p. 5: «Most of the stories remain true to the key-note of the book, its Machiavellian character; they are generally unmoral, and at times positively immoral, in the political lessons they inculcate».

58. Cfr. Ambrosius Theodosius Macrobius, Commentariorum in Somnium Scipionis, II, 6-11.

59. Morten NøjGaARd, La fable antique, Copenhaguen: A. Busck, 1964-1967, vol. I, p. 246284. Els Disthica Catonis, tant llegits a l'occident llatí, també recorden que els forts no haurien de menysprear aquells que són febles de cos però són dotats d'un bon enginy, en uns versos famosos que Raimon de Béziers, ben conscient de la proximitat d'aquest ensenyament amb algun del Calila $i$ Dimna, va posar en boca d'aquesta última en la seva traducció llatina del llibre: "Corporis exigui uires contemnere noli: / Consilio pollet, cui uim natura negauit» (Disticha catonis, II, 9. Cfr. Raimundus De Biterris, Liber Kalila et Dimna, ed. Biblioteca Augustana, http://www.hs-augsburg.de/ -harsch/augustana.html\#la, llibre IV). 
que aprengui a ser també guineu per conèixer les trampes i poder-se'n defensar. Si hem de creure el que ell mateix diu al Llibre de contemplació, Llull podia oferir les lliçons que dóna sobre el frau al Llibre de les bèsties amb cert coneixement de causa. Ramon confessa en aquell llibre que, en el passat, ha dit moltes paraules dobles plenes d'enganys i de sofismes per tal d'enganyar els altres quan aquests s'hi adreçaven sense voluntat d'enganyar-lo i sense astúcia (maestria) i afegeix que, ara, la seva consciència el reprèn d'haver-ho fet i que per això es fa el propòsit de ser obedient a la seva consciència i de no tornar a les "paraules dobles i sofismades», com (l'exemple és seu, però ens fa pensar en el pobre Guido) quan prometia allò que el seu cor no volia complir. ${ }^{60}$ Resulta impossible de saber si Llull va obeir en endavant els dictats de la seva consciència. El que sí sabem és que, en el mateix Llibre de contemplació, manifesta que són els homes falsos i fraudulents els que s'acostumen a emportar tots els honors i que, a la Doctrina pueril, ensenya que tenir prudència, a més de per saber dissimular el secrets, serveix per no ser enganyat ni enganyar perquè cap de les dues coses es convé amb la prudència. I també sabem que, en aquesta última obra, insisteix en la necessitat de concordar la cautela i la maestria amb aquesta prudència, cosa que només és possible si no es cau en la falsedat i l'engany. La seva sentència, adreçada en aquesta ocasió a un nen, és que «saber enganyar i desamar engany és amar prudència» perquè la prudència sap i desama l'engany, i sap i estima la caritat i la justícia. ${ }^{61}$

No recordo que Llull digui obertament enlloc què ha de fer l'home que sabent d'enganys i desamant-los es troba davant la situació d'haver d'enganyar perquè algun motiu honest o útil ho exigeix. ${ }^{62}$ Però en el Llibre de les bèsties, l'elefant, bàsicament perquè tem que la guineu l'acabi traint com vol trair el lleó, no dubta a recórrer a l'engany per provocar que la guineu acabi caient en la seva pròpia trampa. I és com a fruit d'aquesta decisió que el lleó es desfa de la guineu per la força que el caracteritza i que la cort pot tornar, gràcies a uns bons consells d'una altra mena, al seu bon estament. És en aquest mirall que el príncep ha d'aprendre com ha de regnar i com ha de lliurar-se, amb l'ajut de consellers amb maestria, d'aquells que l'aconsellen malament i dels traïdors.

60. «Vos sabets que jo he dites moltes paraules dobles plenes d'engans e de sofismes per tal que pogués enganar e decebre mos pruxmes qui sens tot engán e sens tota maestria me parlaven $\mathrm{e} \cdot \mathrm{m}$ recomtaven lur propòsit e lur entenció e lur volentat. On, com la mia ànima sia remembrant totes estes coses, per assò la mia consciència me reprèn molt fortment com jo call e no parle totes les maestries e.ls engans que he fets ab mes paraules dobles e sofismades" (Llibre de Contemplació en Déu, llibre III, cap. 210, a ORL V, 1911, p. 358-359).

61. «[7] Cautela, maestria se covenen ab prudencia en mercaderia e en les altres arts mecaniques, ab que no y sia falcia ne engan, qui son contraris a prudencia. On, si tu, fil, est amador de prudencia, ages saviea e sciencia, per la qual vules e sapies concordar prudencia e cautela, maestria, sens falsia e engan. [8] Saber enganar e desamar engan es amar prudencia, qui sap e desama engan e sab e ama caritat, justicia» (Doctrina Pueril, cap. 56, NEORLVII, 2005, edició Joan Santanach i Suñol, p. 146-147). Cfr. Ramon Llull, Llibre de l'orde de cavalleria, VI, 7, ed. Albert Soler, Barcelona: Barcino («Els Nostres Clàssics»), 1988.

62. Cfr. Tomàs D’Aquino, Summa Theologiae, II ${ }^{\mathrm{a}}$ - II a, q. 55, a. 3, ad 2: «Unde etiam astutia si ordinetur ad bonum finem, est peccatum.» 
I la lliçó que es pot aprendre en aquest mirall no sembla que coincideixi amb la que Dante sembla voler oferir a través de la història que conta Guido.

Explica Egidi Romà en el De regimine principum que si es vol tractar de l'art i la doctrina dels regiments de prínceps, cal examinar, primer, quina manera de procedir s'escau en aquesta art. I estableix que la manera que li pertoca és la grossera i figurativa. Per tres raons. En primer lloc per la seva matèria, que són els actes humans, en els quals hi ha una gran variabilitat $\mathrm{i}$ incertesa, i que pertany a la disciplina de l'ètica, que no pot aspirar a la certesa de les matemàtiques. En segon lloc, per la seva finalitat, que, precisament en tant que es tracta d'una part de l'ètica, no és la veritat (el conèixer), sinó el bé (l'esdevenir millor). I, en tercer lloc, pel seu auditori, que no només són els prínceps i els nobles, sinó també la totalitat del poble que han de regir. ${ }^{63}$ Aquestes són les tres raons que volen justificar perquè, en la doctrina dels regiments dels prínceps, cal recórrer als arguments poc refinats propis de la persuasió retòrica (que són aquells mouen a la majoria a actuar en una o altra direcció) i a l'ús del mètode figuratiu o exemplar. A l'Epistola a Cangrande, també s'afirma que la filosofia pràctica o ètica és el gènere en què es mou tota la Commedia, un poema que no té com a objectiu el coneixement especulatiu, sinó l'acció. I s'afegeix que tot aquest poema, que té com a objecte l'assoliment de la felicitat, es pot llegir literalment, com si parlés de l'estat de l'ànima després de la mort, o al-legòricament, entenent que parla de l'home que, pels seus mèrits $\mathrm{i}$ demèrits, està sotmès al premi $\mathrm{i}$ al càstig de la justícia. ${ }^{64}$ És en aquest context doctrinal que cal entendre l'episodi de Guido da Montefeltro que es narra a l'Inferno. Cal llegir-lo com l'episodi d'una faula que, com aquelles que van narrar Plató o Ciceró al final de les seves respectives Repúbliques i que tant agradaven a Macrobi, parla literalment en la seva superfície de l'estat de les ànimes en l'altre món, però amaga al-legòricament en el seu interior un discurs més filosòfic, que s'ocupa de la justícia i de l'assoliment de la felicitat en aquesta vida a través de les virtuts morals i intel.lectuals i de la seva pèrdua per l'apartament d'aquestes virtuts. ${ }^{65}$ Guido, a qui en Convivio es descriu com "el nostre molt noble italià» (IV, 28, 8), és a l'infern perquè, en justícia, la infelicitat és el lloc que els pertoca a aquells que s’aparten del camí recte aconsellant un frau, un frau que, en el seu cas, no tan sols ofenia la consciència de tothom, sinó que, a més, anava en contra del bé comú i contribuïa injuriosament a l'augment del poder del pastor que havia esdevingut llop.

El Llibre de les bèsties de Llull també és, com hem vist, un regiment de prínceps. Però, a diferència del De regimine principum d'Egidi o de la Commedia de Dante, l'essencial de la seva doctrina no pertany a aquella part de la filosofia pràctica que la tradició denomina ètica i de la qual Ramon s'ocupa, barrejant-la amb la religió, en molts altres indrets de la seva obra. Allò que

63. De regimine principum libri III, Roma 1556 (Reimpressió: Francfort 1968), I, 1, p. 2r.-2v. 64. Dante, Epistola XIII a Cangrande della Scala, 23-25, 33-34 i 40-41.

65. Macrobius, ibid., I, 1-4. 
s'aprèn del comportament de bèsties com el lleó i la guineu, un coneixement estrictament tècnic sobre la dominació i sobre la força i el frau, cau fora de les fronteres, per bé que és conceptualment a tocar, de la filosofia moral. I no té res a veure amb esdevenir i governar millor, sinó amb conservar el poder o la vida. Però el fet que la disciplina i la finalitat pròpies del Llibre de les bèsties no siguin els dels regiments de prínceps descrits per Egidi no impedeix que, en aquesta obra, també hi operi l'oposició entre els dos discursos que, segons la doctrina sobre la faula, es canalitzen en el mateix text: el superficial i el profund. Com en totes les faules animalístiques, el discurs superficial ofereix entreteniment als nens i als no tan nens que es complauen en els relats de ficció protagonitzats per bèsties parladores. El discurs profund, que només està a l'abast del savis que tenen la paciència de trencar la closca i menjar el fruit, parla, en canvi, d'allò que Raimon de Béziers, en el pròleg a la traducció del Calila i Dimna que va fer per Felip IV de França, anomena el «secreta regalia», el secrets del rei. ${ }^{66}$ D’aquells secrets sobre la part animal de la política que, abans que Maquiavel, donant l'esquena a una llarga tradició, els divulgués en nom propi i obertament, els antics i els medievals ensenyaven de manera velada, mentre explicaven les accions i les paraules fictícies de personatges com el lleó i la guineu.

66. «Documenta igitur huius libri spectant ad secreta regalia pertractanda» (ibid., cap. I). Cfr. Iohannes De CAPuA, Directorium humanae vitae alias parabolae antiquorum sapientum, ed. Biblioteca Augustana (http://www.hs-augsburg.de/-harsch/augustana.html\#la), Prologus: «At propter hoc convenit viro intelligenti, quod quando legit hunc librum, nitatur studere in ipso toto suo animo, et respiciat in eo diligenter, et sciat quoniam liber iste habet duas intentiones, unam manifestam, alteram vero occultam; et nulli valet manifesta, nisi intelligat occultam. Sicut si quis accipiat nuces; non conferunt ei nisi rumpantur, et educatur quod in eis latet». 